\title{
MASTER
}

\section{Evaluation of the General Atomic Codes TAP and RECA for HTGR Accident Analyses}

\author{
S. J. Ball \\ J. C. Cleveland \\ J. P. Sanders
}

Prepared for the U.S. Nuclear Regulatory Commission Office of Nuclear Regulatory Research Under Interagency Agreement DOE 40-551-75 
ORNL/NUREG / TM-178

Dist. Category NRC-8

Contract No. W-7405-eng-26

\title{
EVALUATION OF THE GENERAL ATOMIC CODES TAP AND FECA FOR HTGR ACCIDEN? ANALYSES
}

\section{S. J. Ball}

\author{
J. C. Cleveland J. P. Sanders
}

Manuscript Completed - Apri1 4, 1978

Date Published - May, 1978

NOTICE: This document contains information of a preliminary

nature. It is subject to revision or correction and therefore does not :epresent a final report.

\author{
Prepared for the \\ U.S. Nuclear Regulatcry Commission \\ office of Nuclear Regulatory Research \\ Under Interagency Agreement DOE 40-551-75 \\ Prepared by the \\ OAK RIDGE NATIONAL LABORATORY \\ Oak Ridge, Tennessee 37830 \\ operated by \\ UNION CARBIDE CORPORATION \\ for the \\ DEPARTMENT OF ENERGY
}

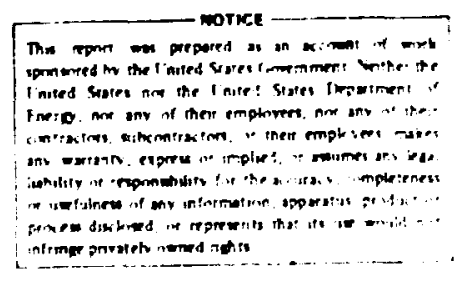

The ront an prepond

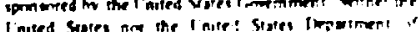

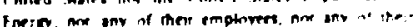

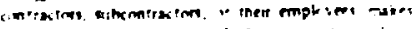

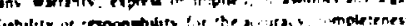

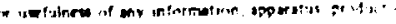

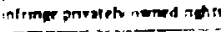


Asstract ......................... 1

1. ImILODOCTIO ..................... 1

2. THE $\operatorname{TAP} \operatorname{con} \ldots \ldots \ldots . . . \ldots \ldots$

2.1 Background. . . . . . . . . . . . . . 2

2.2 TAP's Approach to the Problen ............ 2

2.3 TAP's Susceptibility to youse or Input Errors. . . . . 5

2.4 Comparisons of TAP Predictions wth Those of Other Codes. 6

3. TAE RECA CODE. ..................... 11

3.1 Background. . . . . . . . . . . . . . . 11

3.2 RECA's Approach to the Problem. . . . . . . . . . 11

3.3 RECA's Susceptibility to Msuse or Input Errors . . . . 18

3.4 Comparisons of Rech Predictions with Those of other Codes.................... 20

4. concuustons. . . . . . . . . . . . . . 22

APPEANIX ........................ 27

A.l Review of TAP Report LTR-21 . . . . . . . . . . . 27

A.2 Revies of RECA3 Report LTR-22 . . . . . . . . . . . 30

REFERENCES . . . . . . . . . . . . . . . . . 32 


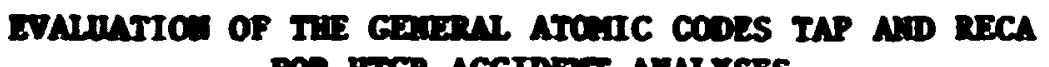

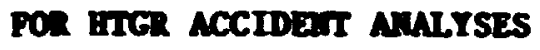

5. J. Ball

J. C. Clevelind J. P. Saoders

Assmect

The Ceneral Atonic codes IAP (Transient Analysis Progran) and wech (Beactor Dergency Cooling Annlysis) are eveluated vith respect to their capability for predicting the dyanic behavior of hightenperature gas-cooled reactors (BTGe) for postulated accident condition. Several apparent oodeling problem are noted, and the enceptibility of the codes to nisuse and input errors is discussed. A critique of code verification plans is also included. The several cases where direct comparisons could be ande between TAP/RECA calculations and those based on other independent 1y developed codes indicated generally good agreenent, thus contributing to the credibility of the codes.

\section{InTRODUCTIOA}

This review of the TAP $^{1}$ (Transient Analysis Progran) and $\operatorname{RECA}^{2,3}$ (Reactor Energency Cooling Analysis) codes is based on work done over - 3-year period in the High-Temperature Gas-Cooled Reactor (HTGR) Safety Analyate Progran at Oak Ridge Nat1onal Laboratory (ORn), which is sponsored by the Division of Reactor Safety Research (RSR), Office of Muclear Regulatory Research, USIRC. Other work relevant to this review was done in sintlar ODN programs sponsored by the Energy Research and Development Adainistration (ERDA) and the Division of Systens Safety (DSS) of the USIRC. It Is Important to note that both TAP and RECA are very complex and sophisticated general-purpose codes. In such cases, the adequacy and accuracy of any given analysis w11 depend strongly on the user's Input data, the severity of the postuleted accident, and other factors that cannot be evaluated on the basis of the codes themselves. In spite of this, however, there have been numerous opportunities to 
me direct comparisons betreen the General Atonic (CA) and independently developed oxul codes, and the agreenent has been generally quite good.

This evaluation includes discussion of the codes' approaches to the problem they address, some apparent nodeling probless, comparisons of a and CuIn analyses, and reviews of the two wost recent TAP $^{1}$ and RECA documents.

\section{THE TAP CODE}

\subsection{Background}

The TAP code' was developed as a means of predicting the dymanic behavior of HTGR nuclear stean supply system (ISSSs) for a vartety of operational and accident cases. It is a flexible, genera1-purpose code that evolved from several "component" codes (e.g., for the core and stean generator). As with any production code of its type, trade-offs between complexity and computing speed ade it necessary to simplify the ajor component models. However, in many cases the simpler models were Jerived from wore comlex ones or from experimental data, and the significant characteristics were retained. Eopecially in vien of the complexity of the overall code, IAP is remarkably efficient.

\subsection{IAP'. Appraach to the Problem}

The philosophy used in the development of the TAP code was that it would be used primarily as a best-estimate code rather than a worst-case or concervative code. However, corservative results can be obtained through proper celection of input purametes. The sensicivity of the predictions to verious sodel and parameter assumptions can easily be 
tested and evaluated. Bealdes its use in safety-related analjses, ThP vas also instrunental in developing HTGR plant control and safety systeas. Host of the detall in the IAP code is concentrated in the primary systen. The reactor core sodel utilizes a single-average-channel approximation (an equivalent cylinder with the coolant at the center surrounded by concentric ringa of graphite moderator am: fuel) divided Into 8 radial and 18 axial nodes and a point neutron kinetics approximation with 6 delayed neutron groups. The core model 18 primarily intended for at-power simulations and is not valld for andyses of very-Iowcore-flow accidents, wich are relegated is the RECA code. Accidents involving very large and sudden reactivity insertions would also be beyond the domain of TAP because of the point neutron kinetics assumtion. TAP utilizes fairly detailed models of the reheater atean generator (which uses a single-average-tube approxtation), the circulator turbine, and mjor plant control and safety systens, whlle most of the belance-of plant (BOP) components are wodeled with very simple algebraic inputoutput relationships. The multiple coolant loops of the HTGR are approxinated by a ingle average loop; therefore, postulated component failures that require a wit\$loop capability sannot be analyzed directly. Component relocation or welting accidents are also not nodeled.

In general, TAP uses detailed correlations for experinentally derived mterial and coolant properties, and well-established heat transfer and pressure drop equations.

In reviewing the TAP report, we found it to give a clear, thorough, and adequately detalled technical description of the modeling techniques and methode of colution. Same of the more important apparent problea 
areas are discussed here, and a nore detalled review of the TAP report appears in the Appendix.

1. The coolant-channel-centered cylindrical model for the core may give unrealistic predictions of fuel and noderator temperatures:

The core thermal nodel description implies that the radil of the fuel and moderator "cylinders" In the coolant-channel-centered singlechannel cylindrical geonetry nodel are deterained on the basis of their total cross-sectional areas. If the effective conductances between nodes within ihe fuel and noderator are not "adjusted" to account for their actual geonetries, both the short-tern (high-frequency) response characteriotica and the changes in average temperatures with power level and the reaultant reactivity feedback - would be In error, regardless of how many nodes are used. If such "adjustments" are made in TAP, they should be noted. Also, if a triangular-shaped element is used to represent a typical channel, the ratio of heat generation $Q$ to heat capacity $M_{\mathrm{p}}$ Is significantly greater $(\sim 30 z)$ than the average $Q / M C_{p}$ for an entire fuel element, and this, In turn, is greater than the average for the entire core. As a result, assumptions of $Q / M C$ which are conservative for one case may not be for others. Calculations of the response of average fuel and average moderator and outlet gas temperatures to transients involving changes in power, flow, and inlet gas temperature should be made for the simplified coolant-channelcentered wodel for comparison with the actual triangular cell model to justify its use.

2. The limitations of using a simplified, algebraic input-output model for the BOP are not clearly identified: 
In the development of the ORTAP code, 4,5 we considered the use of a detailed BOP model to be necessary in order to adequately represent the coupling between primary and secondary systens. In particular, the circulator-turbines derive the exhaust steam, and so a detailed representation of the components affecting this steam supply should be given. Modeling of the feedwater heaters, deaerators, and turbine extraction Iines in detafl may also have a significant tert on the predicted steam generator feedwater temperatures.

3. Neglecting the rotar: moment of inertia for the circulatorturbine may cause underestimation of the primary system flow during coastdowns:

In ORTAP simulations, we have found that neglecting the moment of inertia of the circulator-turbine rotor (as is done in TAP) gives significantly different results for certain transients. This was true for both the large HTGR (LHTGR) and the Fort St. Vrain (FSV) circulator simulations.

\subsection{TAF's Susceptibility to Misuse or Input Errors}

Our direct experience with operating the TAP code has been 11 mited to our Implementing the 1975 LHTGR version on the ORNL IBM 360 computers and running several test cases. This effort was hindered by the fact that a comprehensive user's manual and up-to-date, detalled input instructions were not avallable to us.

A 12-page printout of the Input data for an example TAP transient' gives an indication of both the complexity and flexibility of the code. In such cases, it is obvious that casual users could easily misuse the 
code and, unless they understood the oodels and their limitations, could end up with inconsistent and erroneous results. Once a consistent, "correct" data set is generated, however, it appears that paranetric studies (involving changes in a few parameters) could be run with relatively low probability of error. It is probably safe to assume that the prime users of IAP, (1.e., GA) are well aware of the model assumptions and limitations and have carefully documented input data sets for a variety of cases.

TAP's susceptibility to misuse could be reduced significantly, at least for the case of implementing major design or model struc:ure changes, If the component parts of $\operatorname{TAP}(e .8 .$, the core, stean generator, etc.) could be isolated and tested separately. It is our understanding that this capability doesn't presently exist.

\subsection{Comparisons of TAP Predictions with Those of Other Codes}

One of the objectives of the RSR-sponsored HTGR safety work at ORNL was to Implement the TAP code on the IBM computers at ORNL so that comparisons could be made between TAP computations and those generated using the ORTAP-FSV program. No direct comparisons of output can be made, since the version of TAP implemented is set up to simulate the LHTGRs; however, the general features of the responses are comparable. For example, in both cases, following a turbine trip, the hellum flow decreases to a minimum value and later increases (by action of the control system) because the main steam temperature is below the set point value. Subsequently, the helium flow decreases due to she duindling steam supply. 
Several more direct comparisons were made of the component response features. In the CORTAP report, ${ }^{6}$ a comparison was made of the steady-state core temperature conditions at 1007 power (Fig.1), and the agreement was excellent. Sensitivity studies made with the CORTip code to determine the optimum node spacing for the fuel and graphite showed that 4 and 2 radia: nodes each for the fuel and graphite, respectively, were suffictent for the fast reactivity insertion cases. In the TAP code, normally there are 3 radial nodes each for each axial fuel and graphite section; this should be suffictent also, assuming that the thermal conductance of the coolantcentered model is corrected properly (Sect. 2.2). Our studies also showed that the 16 axial nodes typlcally used in TAP for the core are sufficient over the helium flow range for which the code is intended.

Sone comparisons were also made of the steam generator responses predicted by TAP and by BLAST, ${ }^{7}$ which is the steam generator subroutine portion of the ORTAP code. In all cases that were run, the agreement was very good in spite of the fact that the models used are quite different. Both codes use fixed node boundaries and model a single average tube. BLAST solves the time-dependent conservation of energy, mass, and mompntum equations in each node for both the water and helium sides in both the econcmizer-evaporator-superheater (EES) section and the reheater. In TAP it 18 assumed that the water-side pressure in each of the three EES sections is uniform, and incompressible flow 18 assumed for both fluids. An example comparison" for a design-basis depressurization accident (DBDA) transient is shown in Fig. 2. As can be seen in the figure, the agreement is excellent. 


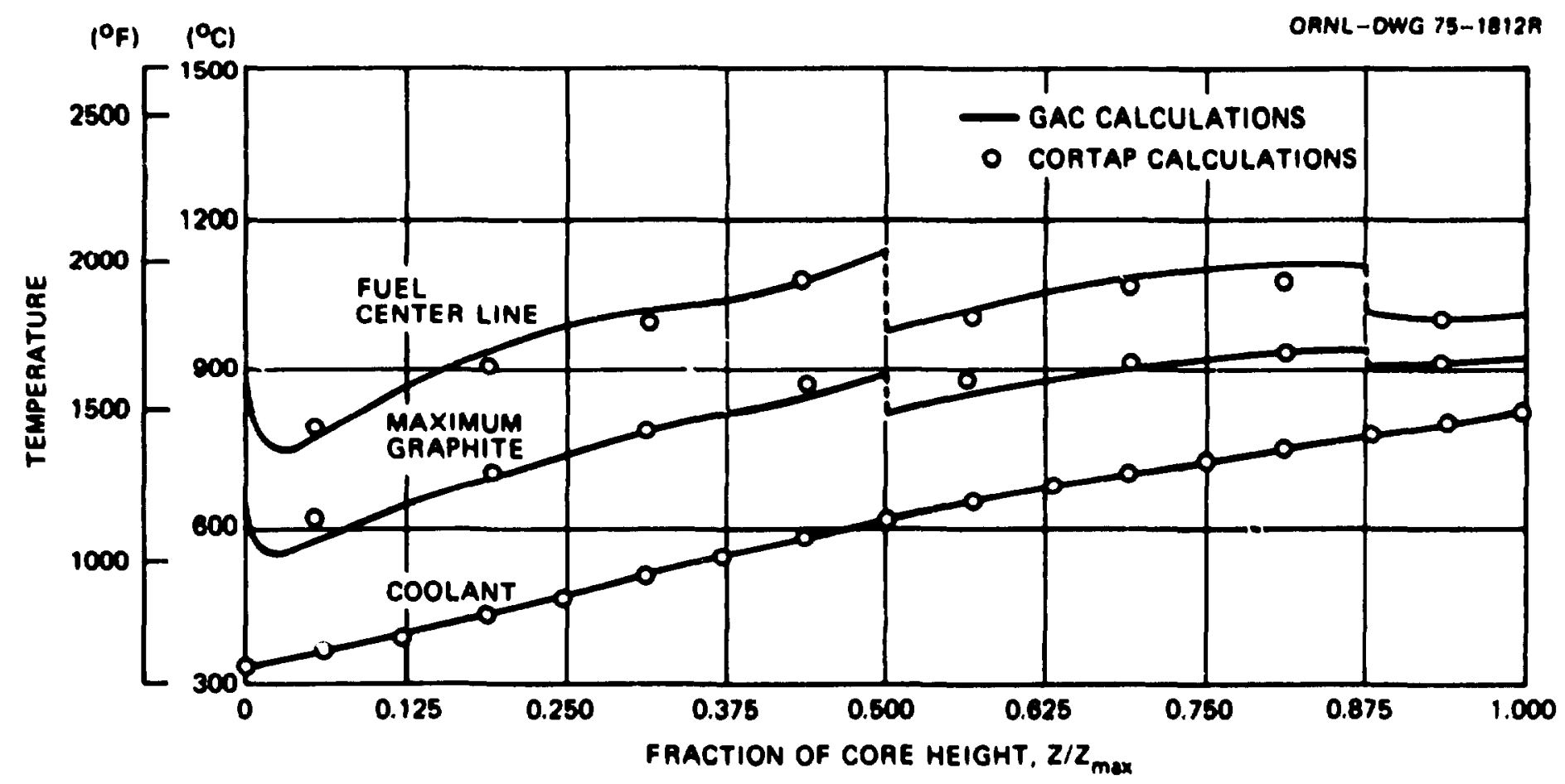

Fig. 1. Comparison of GAC and ORNL steady-state axlal core temperature distribution. 


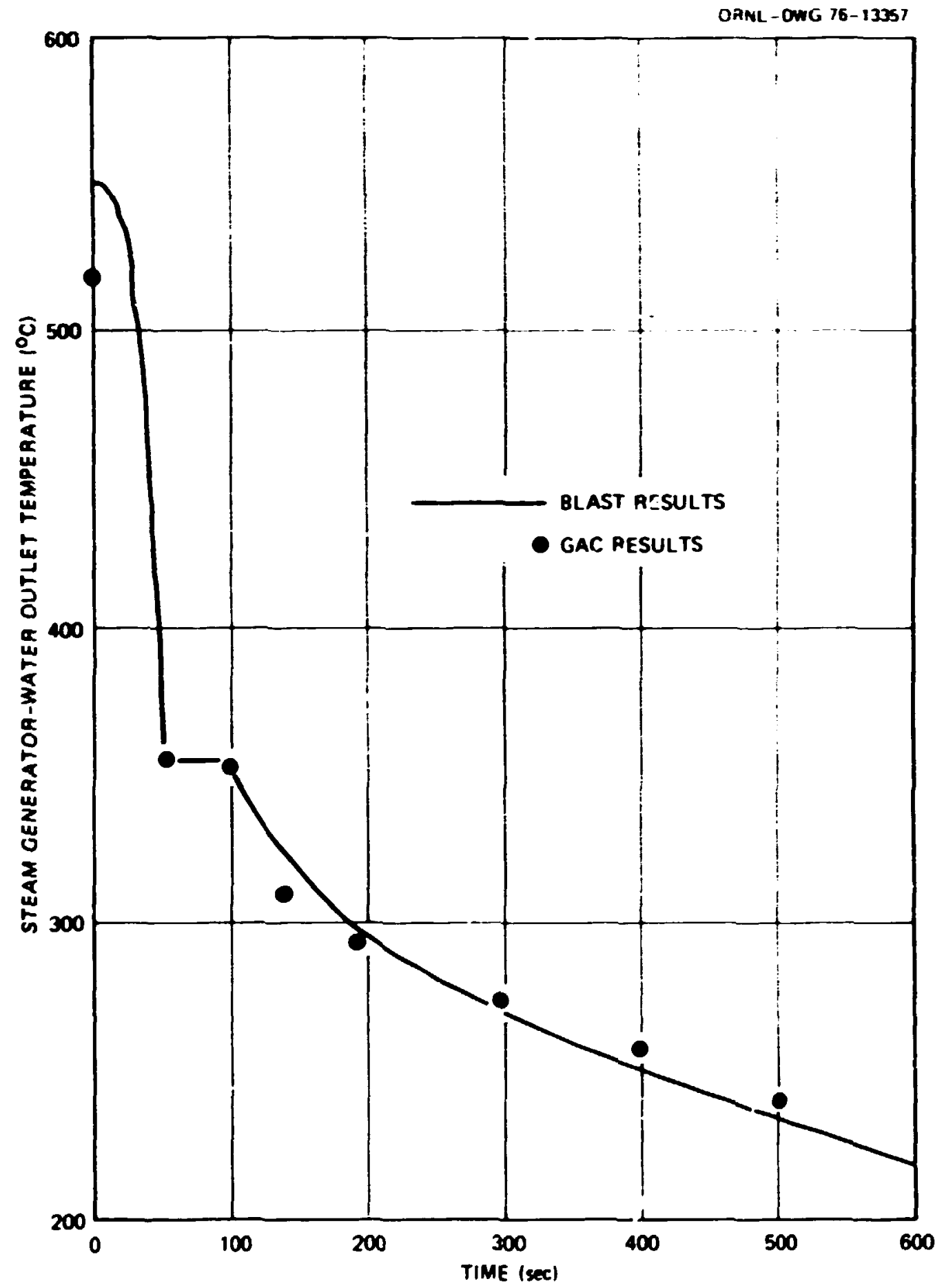

F1g. 2. Steam generator water outlet temperature following initiation of a DBDA $\left[{ }^{\circ} \mathrm{F}=9 / 5\left({ }^{\circ} \mathrm{C}\right)+32\right]$. 
ORnL studies of FSV rod pair withdrawal accidents were done recently,"10 and many of the cases corresponded directly to TAP-generated cases. ${ }^{11}$ Where comparisons could be made, the agreement was good. Table 1 shows the conditions for three such cases. In the two cases in which the scras signal was reheat stean temperature (RHST), the dynamics of the primary and secondary loops and the plant control systems affect the time of scram and thus all the maximum temperatures. Note that the scram times for TAP and ORTAP are only $2.5 \mathrm{sec}$ apart out of $>100 \mathrm{sec}$.

*. Table 1. Results of rod pair withdrawal transients from $100 z$ power

\begin{tabular}{|c|c|c|c|}
\hline & \multicolumn{3}{|c|}{ Case } \\
\hline & $1^{a}$ & 2 & 3 \\
\hline $\begin{array}{l}\text { Rod worth, } \Delta k \\
\text { Initial position of rod patr } \\
\text { Kinetics parameters } \\
\text { Scram signul } \\
\text { Time at scram initiation, sec }\end{array}$ & $\begin{array}{l}0.012 \\
\text { Fully in } \\
\text { EOC-EQ } \\
\text { RHSTb } \\
102.5 \\
(105)^{\mathrm{C}}\end{array}$ & $\begin{array}{l}0.012 \\
\text { Pully in } \\
\text { EOC-EQ } \\
140 \% \\
39.2\end{array}$ & $\begin{array}{l}0.010 \\
\text { Fu11y in } \\
\text { EOC-EQ } \\
\text { RHST } \\
108.4\end{array}$ \\
\hline $\begin{array}{l}\text { Power level at scram initiation } \\
\text { Maximum core average fuel temperature, }{ }^{\circ} \mathrm{C} \\
\text { Maximum mixed mean core out let } \\
\text { temperature, }{ }^{\circ} \mathrm{C} \\
\text { Region experiencing rod withdrawal: }\end{array}$ & $\begin{array}{l}282 \\
1195 \\
(1225)^{c} \\
994^{d} \\
(1062)^{c}\end{array}$ & $\begin{array}{l}140 \\
861 \\
(8 \% 0) c \\
801 \\
(\leq 796) c\end{array}$ & $\begin{array}{l}253 \\
1146 \\
(1116) c \\
962 \\
(1002) c\end{array}$ \\
\hline $\begin{array}{l}\text { Peak centerline temperature, }{ }^{\circ} \mathrm{C} \\
\text { Peak region out let temperature, }{ }^{\circ} \mathrm{C}\end{array}$ & $\begin{array}{l}3057 e \\
(2870) c \\
1654 \\
(1650) c\end{array}$ & $\begin{array}{l}1137 \\
(1183)^{c} \\
862 \\
(\leq 914)^{c}\end{array}$ & $\begin{array}{l}2685 e \\
(2364)^{c} \\
1496 \\
(1414)^{c}\end{array}$ \\
\hline
\end{tabular}

a Reference case.

byeasured reheat steam temperature $42^{\circ} \mathrm{C}$ above normal.

CValues derived from TAP calculations shown in parentheses.

$d_{A t}$ initial steady-state conditions, the core average fuel temperature is $816^{\circ} \mathrm{C}$; nixed mean coolant outlet temperature $\&$ s $774^{\circ} \mathrm{C}$; peak fuel centerline temperature $181064^{\circ} \mathrm{C}$; and region outlet helfum temperature is $785^{\circ} \mathrm{C}$.

Ealculation neglected latent heat of fusion of $\mathrm{UC}_{2}$ kernals at $2500^{\circ} \mathrm{C}$ by extrapolating a homogenized fuel st ick heat capacity beyond $2500^{\circ} \mathrm{C}$. 


\section{THE RECA CODE}

\subsection{Background}

The RECA code was developed to analyze postulated accidents which result in a loss of normal core cooling and a subsequent rellance on the emergency cooling systems. For such accidents, it is essential that the analyses include a three-dimensional model of the thermal-hydraulic behavior of the core. For normal power and flow operation, almost all the heat generated in a refueling region is removed directly by convection heat transfer to the hellum coolant, and the flow through each refueling region is established as a fixed fraction of the total core flow by the region's variable orifice setting. Hence, for normal conditions, a singleaverage-channel core model would be approprlate, and hot-channel calculations can be made by simulating the channel of highest power density, and therefore, highest flon, as is done in TAP' and CORTAP. 6 However, for very-low-flow situations, a significant fraction of the heat removed from a region may be by means of conduction radially to an adjacent region. Furthermore, the fraction of the total core flow through a refueling region will vary markedly as the effective flow "resistances" of the reglons become less dependent on the orifice settings and more a function of temperature-dependent channel friction and bouyancy effects. Clearly, for the case in which the flow reverses in some channels, which can occur If the system remains pressurized, the original core flow distribution pattern has been markedly disrupted.

\subsection{RECA's Approach to the Problem}

The RECA code concentrates most of 1 ts detailed modeling on the core and may rely on other codes, such as TAP, OXIDE-3, ${ }^{12}$ and RATSAM, ${ }^{13}$ to 
provide interface information, such as core net flow, coolant inlet temperature, and, in the case of ingress accidents, coolant composition data.

Interregion conduction in the core is typically modeled by using a single node to represent each refueling regton block, which nornally consists of a cluster of seven hexagonal fuel colums, each $\sim 355=(\sim 14 \mathrm{ln}$. across the flats by $-787 \mathrm{~mm}(-31 \mathrm{in.})$ long (Fig. 3). Six of the refueling regions around the perimeter have only five fuel colums. A sevenelement block welghs $-900 \mathrm{~kg}$ ( $\sim$ ton); so this typical RECA core node represents a rather large mass. RECA also typically uses one node each for the upper and lower reflector blocks and the core support block associated with each refueling region. The side reflector for each axial section [e.g., adjacent to a 787-long (31 in.) fuel block] is typically modeled by a single node corresponding to the entire ring of reflector blocks encircling the core (Fig. 4).

The coolant flow through each of the refueling regions is calculated by an iterative scheme which satisfles the input specification of total

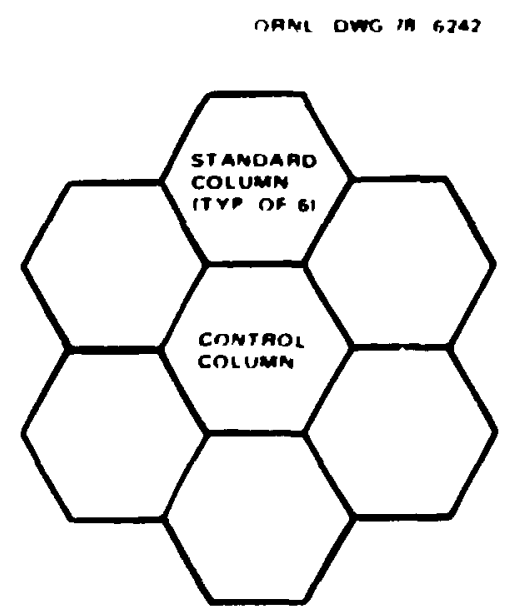

Fig. 3. Plan view of typical refueling reglon. 


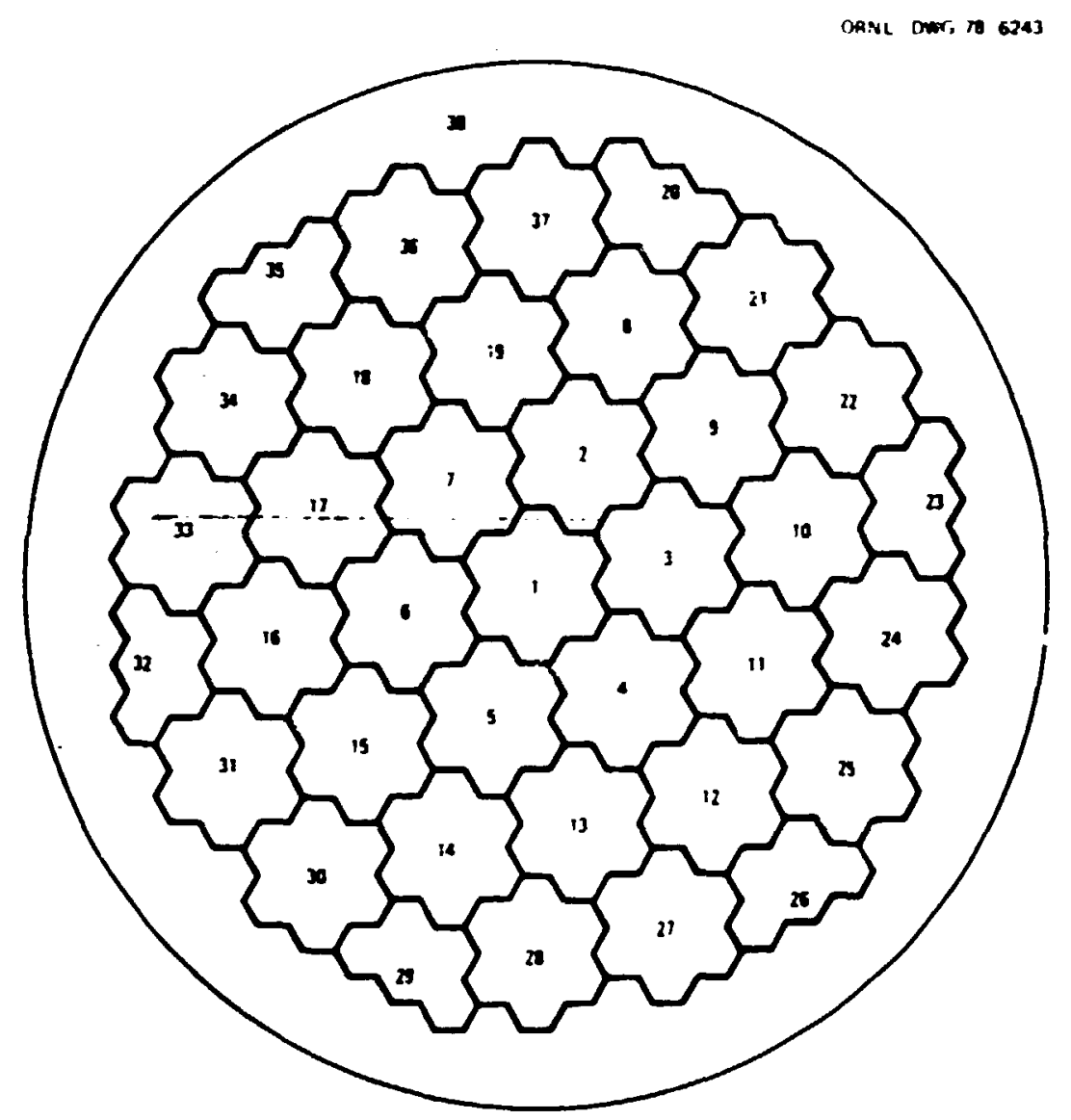

Fig. 4. Typical RECA code radial subdivision of the Fort St. Vrain core model.

net core flow and at the same time ensures that the pressure drops across all regions are equal (1.e., the pressure gradients in the upper and lower plenums are assumed negligible).

The calculation of heat transfer between a solid node and the adjacent coolant uses an end-point-weighting (EPN) model, in which the mean temperature of the coolant is assumed to be equal to the exit temperature of the coolant from that regton.

Thrnughout the code, detalled equations and correlations are used for solid and coolant node properties and regime-dependent pressure drop and heat transfer characteristics. 
Nuclear kinetics are not simulated, and since the gross lumping scheme for the refueling region blocks akes no distinction between fuel and moderator temperatures, It would be difficult to incorporate in the model. Hence, total core power vs time is defined as an input function. The spatial distribution of the core's relative power density is input as a three-dimensional function and is assumed to stay constant during a transient.

Special provisions are made for modeling other core and primary system components and for analyzing special cases such as water and atr ingress accidents. A block diagram of the overall RECA 3 modeling scheme ${ }^{3}$ is shown in Fig. 5.

In general, we have found that $\mathrm{GA}^{\prime} \mathrm{s}$ approach to the problem has been sound, that the model developments and assumptions have been reasonable, and that the documentation ${ }^{3}$ (RECA3) 18 very well written and usually contalns adequate detalls on the models and methods of solution. Several of the more signif Icant problem areas are discussed below, while a more detalled review of the RECA3 report is given in the Appendix.

1. The potential problems with interfacing RECA and TAP are not clearly identified:

For the case of the LHTGR (ca. 1975), RECA Includes a model of the entire emergency cooling loop with the core auxillary cooling system (CACS). Herce, for LHTGR accidents in which the normal primary loop is not involved, no interfacing with the TAP code is required. For LHTGR accidents in which the primary loop cooling 18 significant and for all FSV reactor accidents, TAP-generated input (core Inlet temperature and flow vs time) is required for RECA. In the RECA3 report, it is implied 
ORNL .OWG 78-6244

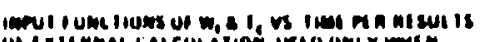

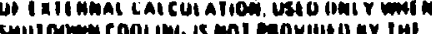

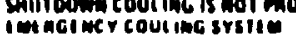

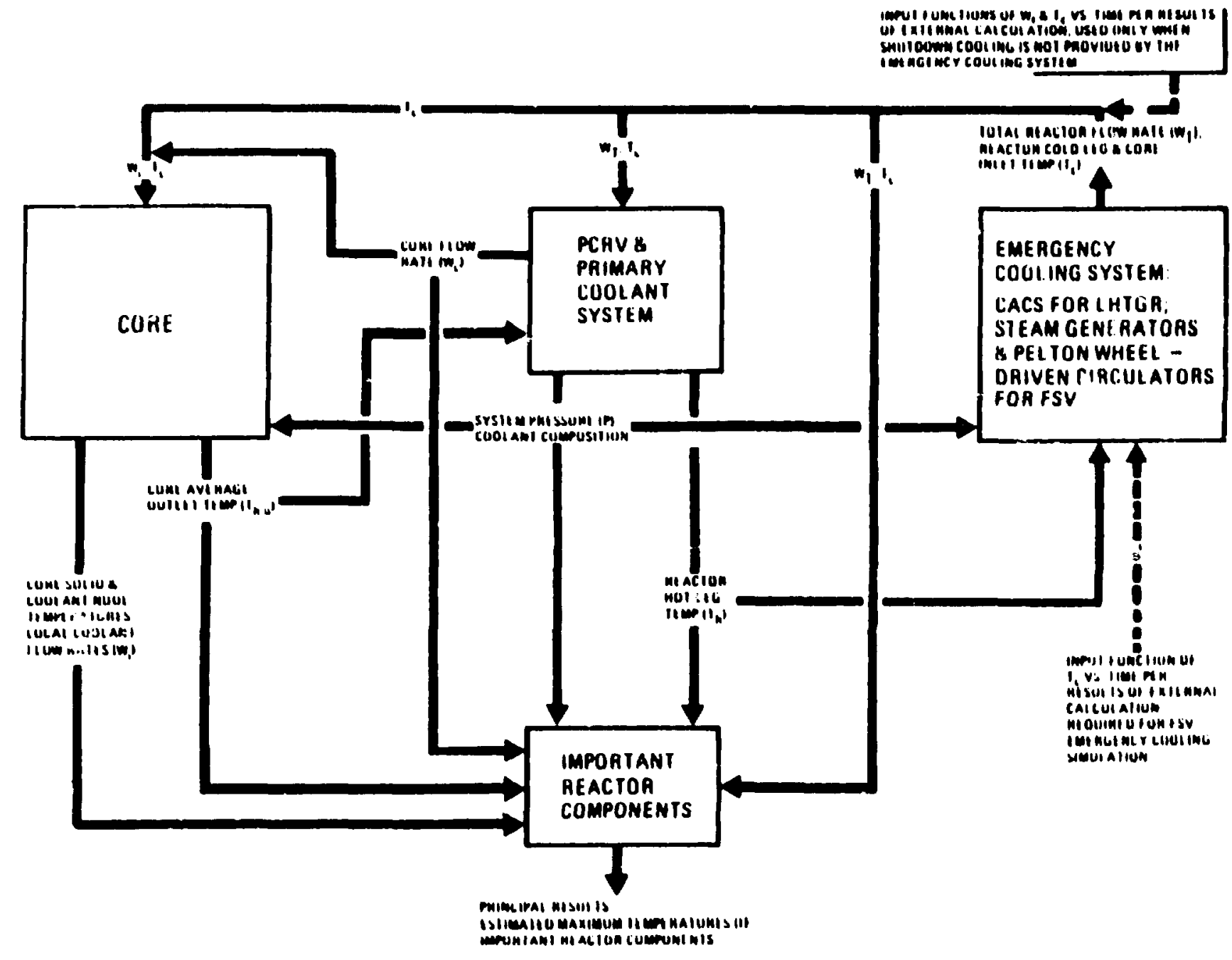

Fig. 5. Main aygtem of arilytical models (RECA3). Source; RECA3: A Computer Code for Thermal Analys1s of HTGR Emergency Cooling Translents, GA-Al4520 (GA-LTR-? 2), August 1977. 
that the behavior of the distributed (RECA) core need not be considered in (or fed back into) the TAP calculation. However, in general, we would expect both the core out let temperature and pressure drop to be different In the RECA and single-average-channel (TAP) calculations and thus affect the TAP-deternined values of core inlet temperature and flow.

2. The afterheat generation curve following a reactor trip appears to decrease too rapidly:

The equation for the FSV afterheat (Eq. 4-8, Ref. 3) appears to apply to a hypothetical case in which the prompt (neutron) power falls to zero instantaneously, while for an FSV scram in which it is (conservatively) assumed that all the rods are inftially fully withorawn and take $152 \mathrm{sec}$ for full insertion, the resulting decrease in total power is much slower (Fig. 6). The use of such slower-scram curves results in significantly higher fuel and coolant temperatures for certain accidents.

3. The assumption of instantaneous depressurization for all blowdown accidents limits the scope of accidents that can be analyzed:

It appears that with minor additions to the RECA model, cases Involving more gradual depressurizations than a DBDA could be simulated. Such a feature would be particularly useful for investigating potential core flow reversal problems and for evaluating CACS blower performance at intermediate pressures in the LHTGRs.

4. The assumption of a single ring-shaped node for the side reflector at each axial level may lead to nonconservative peak temperature predictions:

In studies of FSV DBDAs using the ORECA code, ${ }^{14}$ there were some cases in which the inaximum refueling region temperatures occurred in 
GRN: UAC, !) 19658

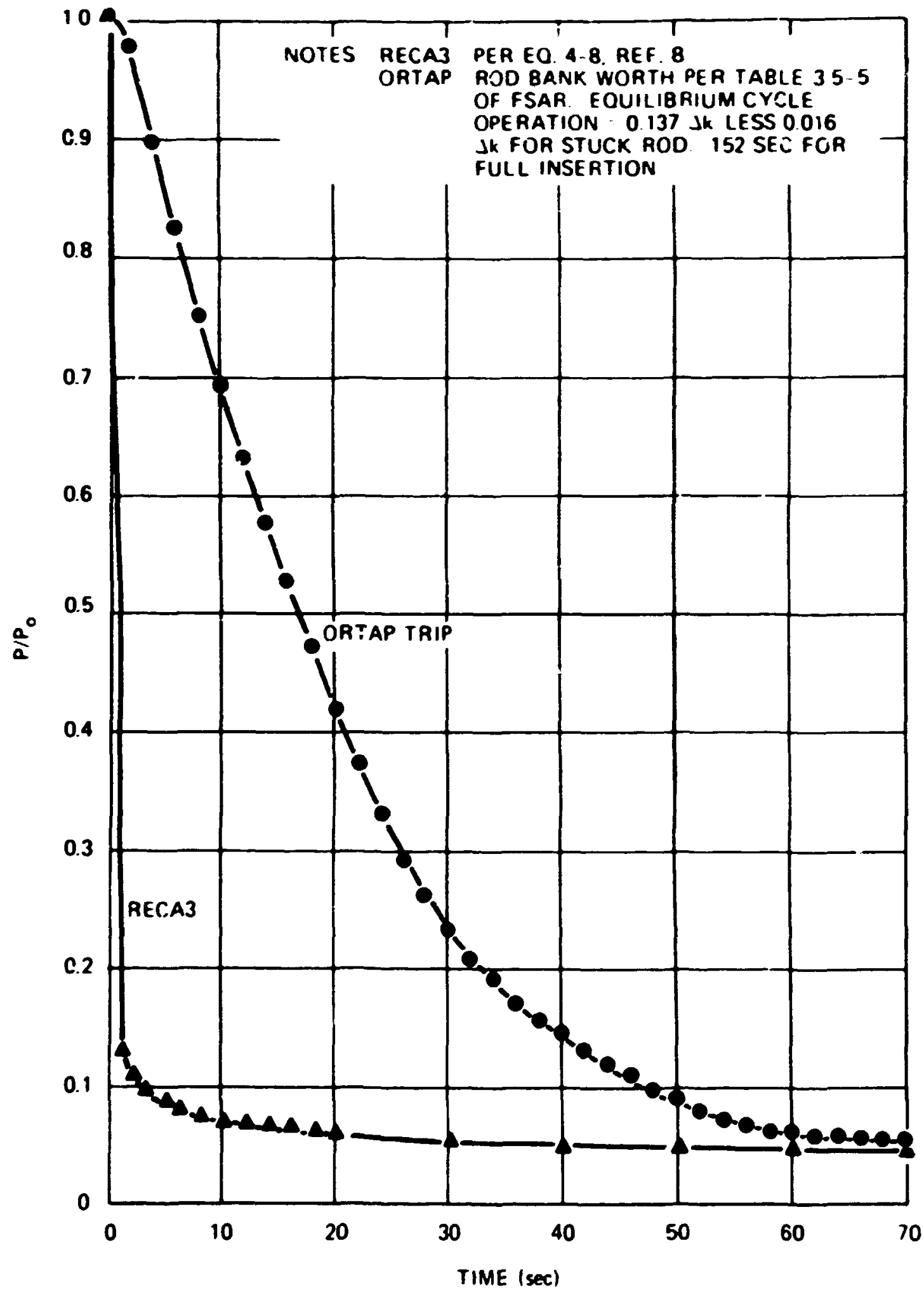

F18. 6. Comparison of RECA3 and ORTAP total core power vs cime af cer reactor trip. 
blocks at the side reflector boundary, and a significant amount of the heat generated in these blocks was removed by conduction to the adjacent side reflector nodes. It appeared that if the side reflector had veen modeled by "average-ring" nodes instead of individual blocks (as in ORECA), the higher heat capactity and lower average temperature of the large rings would have provided an unrealistically good hat sink for the hot regior..

\subsection{RECA's Susceptibllity to Misuse or Input Errors}

Our only direct experfence with the RECA code has been our attempt to implemest it on the TBM 360 computers at ORNL. This Implementation profect has been a low-priority job, which began in early 1975 and has not yet resulted in a successful RECA run. Many of the problems were related to the different FORTRAN versions used and to the fact that several binary tape implementation steps were required. Also GA's Univac 1110 and the IBM 360 use different computer word configurations. Another major impediment was the extremely complex procedure required to run a case with the 1975 version of RECA. (The RECA3 User's Manual ${ }^{15}$ is not yet avallable to us.) A detalled description of this procedure was written by J. P. Sanders ${ }^{16}$ and is sumarized in block dlagram form in Fig. 7. Subsequently, it was learned that the FORTRAl programs created by the preprocessor program (CINDA-3G), 17 which are designated the stendyState RECA and Transient RECA prgrams, are typically not used by GA. Instead, verstons of these programs which were generated several years before are modified to suit the spectfic problem. And, currently, the CINDA-3G preprocessor 18 executed only to produce the packed binary data tape. The size of the defined arrays in the RECA programs must be modified manually to accomolate change in nodal structure. 
OANL - OWG $75 \cdot 5511$

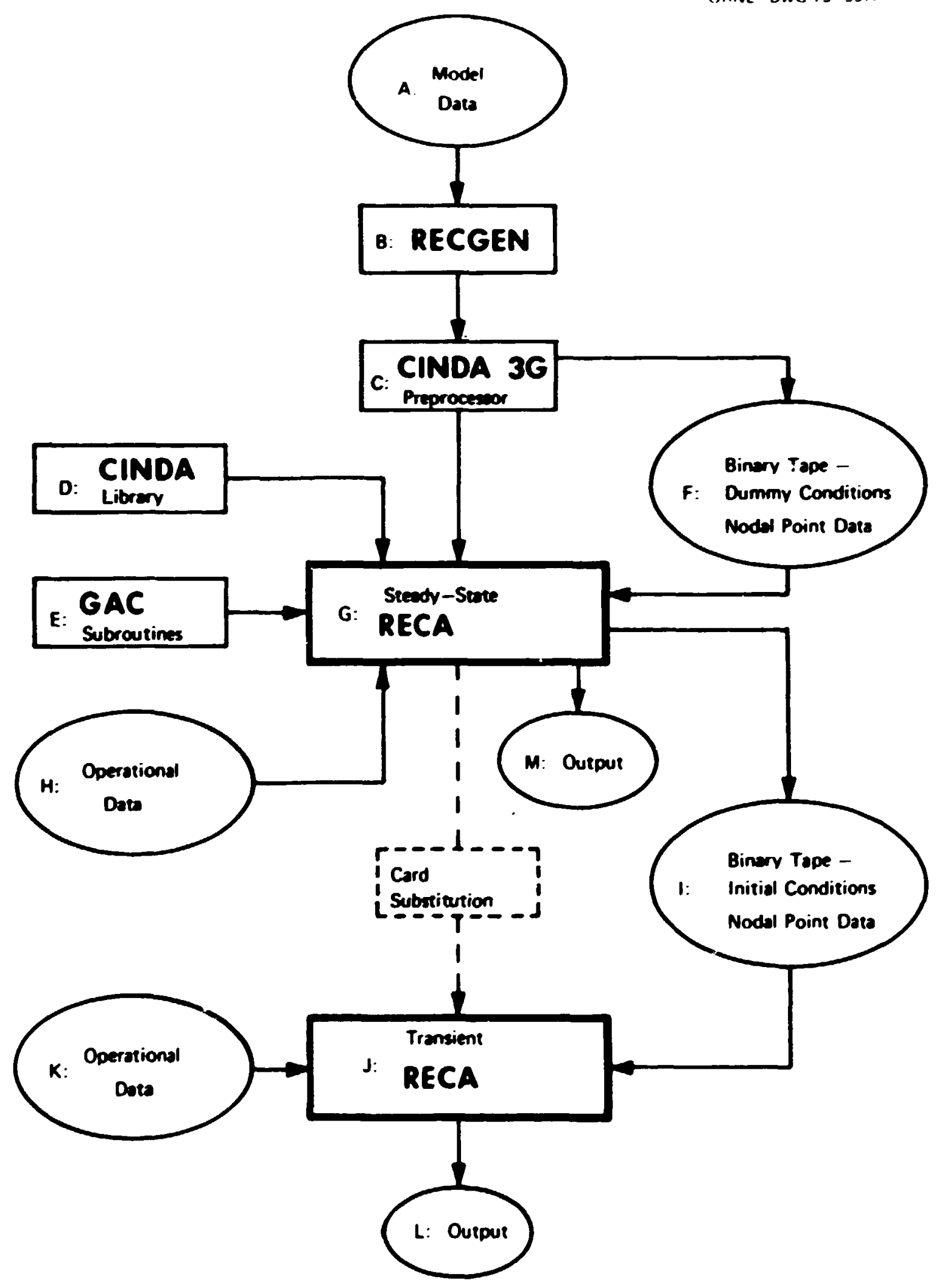

F1g. 7. Overall procedure for the execution of the RECA program. 
The use of a nodal-point generator (RFCCEN, Fig. 7) and a preprocessor (CINDA-36) both tend to reduce the susceptibility of the code to input errors. However, the unusually complex procedure required to run a case would appear to us to far overshadow the advantages of using RECGEN and CINDA-3G, at least in terms of RECA's "ease of operation." In short, it appears that RECA (1975) is relatively susceptible to misuse and input errors.

\subsection{Cosparisons of RECA Predictions wth Those of Other Codes}

Several Independent calculations were performed at ORNL to deterwine the response of the FSV reactor to a specific DBDA. GA also performed calculations for the same accident assumptions using RECA; therefore, direct comparisons can br made. In this postulated accident, it was assumed that only two of the four auxiliary (Pelton wheel) drives operate their respective circulators and that the circulator speeds are reduced from the normal $10,550 \mathrm{rpm}$ to $7,000 \mathrm{rpm}$. The core inlet temperature and net flow histories were provided by GA from a TAP code calculation and were used in both the RECA and ORRL codes. The initial core power level was assumed to be $105 \%$, and the initial regional flow distribution was adjusted such that the helfum out let temperatures from all regions were equal. Following the DBDA, the effective adjustable-orifice pressure drop coefficients were assumed to remain constant.

Predictions by the ORECA code, " shown in Fig. 8, indicate good agreement with RECA results, especially considering that the maximum core region outlet cemperature is the limiting factor in the DBDA. (This is due to the fact that the temperature limits of lower core thermal barriers which are exposed to the outlet gas are approached more closely 


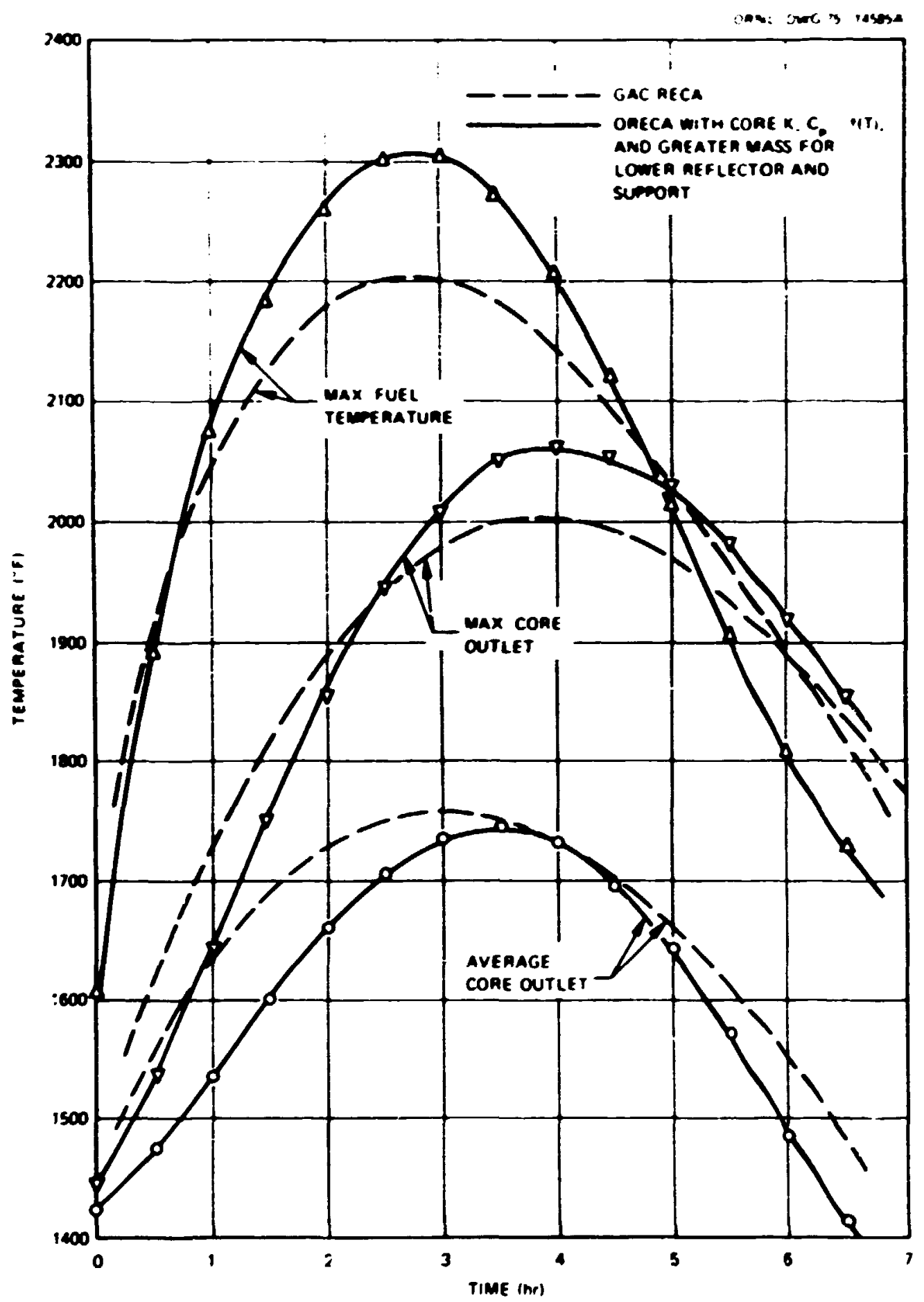

Fig. 8. Predicted system response of the Fort St. Vrain plant to a depressurization accident $\left[{ }^{\circ} \mathrm{C}=5 / 9\left({ }^{\circ} \mathrm{F}-32\right)\right]$. 
than are the fuel temperature limits.) The ORECA results indicated in Fig. 8 note that core conductivity $(K)$ and specif ic heat $\left(C_{p}\right)$ values are included as a function of teaperature $(T)$, and that a "greater mass" is assumed for the lower reflector and core support blocks. This is to denote distinctions between this and previous analyses in which conservatively low (constant) values of $K$ and $C_{p}$ were used and the lomer core mass was underestinated.

A second ORML RECA-like code called FLODIS, ${ }^{10}$ developed under DSS sponsorship, was also used to analyze the sase DBDA, and a comparison of the results with RECA predictions is show in Fig. 9. The major difference between the FLODIS model and those used for RECA and ORECA Is that FIODIS uses rectangular (rather than hexagonal) radial mesh spacing for the core structure nodes, and the nodal spacing used for the DBDA analysis reported was much finer than either RECA or ORECA's. The main reason given $^{10}$ for the higher temperatures predicted by FLODIS is that the finer mesh spacing in FLODIS accounts for temperature gradients and flow distributions within the refueling regions. In spite of these differences, the results are still comparable.

\section{CONCLUSIONS}

The most recent technical reports describing the TAP $^{1}$ and RECA $^{3}$ codes are wellwiten, useful documents. They both give enough detalls to evaluate the modeling and solution techniques, but not the coding detalls. The approach used in most of the model development was based on first principles and is thus likely to avold the serious errors that can occur If the alternative (1.e., "black box") models are used and applied beyond their uorful range. 


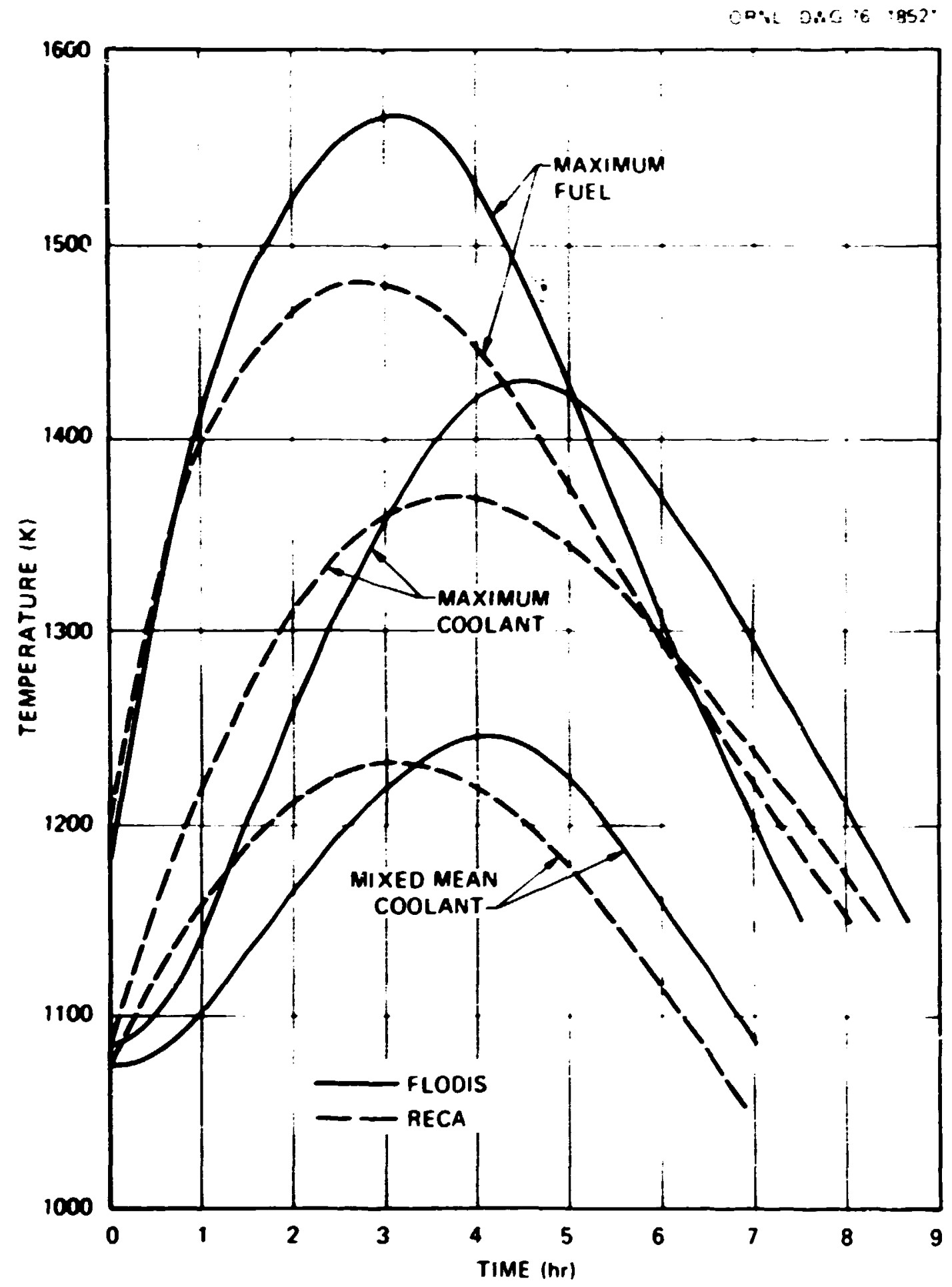

Fig. 9. Comparison of FLODIS and RECA temperatures during a postulated Fort St. Vrain DBDA with 7000 rpm circulator speed $1^{\circ} \mathrm{F}=9 / 5(\mathrm{~K}-$ 273.15) + 32]. 
Considerable flexibility has been built into the codes to allow for simulation of a variety of component designs, for adjustment of node spacing, and for varlation of model parameters and controlier parameters, etc. Along with the benefits of such flexibility, however, comes the enhanced susceptibility to user input errors. We have concluded, however, that it is safe to assume that GA has carefully generated, we11-documented, and error-free data sets for the standard HTGR designs and operating conditions, thus lending confidence to the results they generate. The remarkably complex procedure required to run RECA (1975), however, tends to shake this confidence.

Both TAP and RECA have a long history of development and use for a variety of designs and transients, of use and scrutiny by many different Investigators, and of extensive use for sensitivity studies. There have also been numerous comparisons made both with simpler and more complex codes (at least for the ur.jor couponents), and the comparisons have generally been satisfactory, as noted earlier in this report. All of these factors contribute to the credibility of the results that GA generates.

The most satisfactory way of enhancing code credibility is, of course, by (good) comparisons with actual HTGR transients. Program plans for making such comparisons are outlined briefly in the two reports. ${ }^{1,3}$ We have found, however, that it is typically not sufficient to make comparisons of theoretical computations vs experimental data that rely on data derived from "normal operating transients." Much care and planning is required to ensure against extraneous perturbations such as unexpected or unrecorded operator actions. In particular, in order to verify dynamics codes, it Is necessary to design the input perturbations so that the dynamic features 
of the component of interest will be excited and measured properly. We feel that CA should pursue detailed verification plans and tests more aggressively. The utility that owns the plant, Public Service of Colorado, would benefit from such tests by using confirmation data to reduce the uncertainty, which would reduce the imposed conservatism in the predictions and hence relax operating restrictions.

Several possible problem areas in the codes' models and assumptions are discussed in Sects. 2.3 and 3.3; other less significant points are mentioned in the reviews of the reports in the Appendix. 


\section{APPENDIX}

\section{A.1 REVIEW OF TAP REPORT LTR-21}

The following cownents supplement those made in Sect. 2.2 and are listed by TAP report section number.

Sect. 1. The Introduction would be a good place to state what types of transients can and cannot be reasonably predicted by TAP. For example, TAP to not intended for use with very-10w-flow (RECA-type) accidents, nor with component fallures that require a multiloop capability, nor with effects of core or primery circuit component relocation.

Sect. 2.1 The report Indicates that there 18 coolant flow through the reserve absorber channels. Design drawings revlewed at ORNL seet to indicate that this is not the case; the reserve absorber channels are closed at the bottom to contain the reserve absorber spheres.

Sect. 2.2 In Sect. 2.2.1, It is stated that TAP uses the spaceIndependent, one-energy-group neutron kinetics model with $81 x$ groups of delayed neutron precursors. Some indication of the range of validity of this approximation should be included; for example, Ref. 19 indicates that this model would oignificantly underestimate the peak core power during a transient resulting from a fast rod removal transient (rod efection) with a reactivity insertion of $-\$ 2.00$ in $0.1 \mathrm{sec}$.

It is not apparent from the discussion whether significant differences in the response of temperature reactivity feedback are seen when the optional scheme (Eq. 2-16) of including moderator material in the fuel region is used. Figure 2.6 Indicates that che fraction of total worth for all rod pairg 18 skewed much more coward the lower portion of che 
core than is the fraction of total worth for one rod pair. The extent of the skew appears to be greater than for corresponding light-water reactor curves. Reasons for this should be included.

It is noted in Sect. 2.2.6.5 that a decay heat equation is in Sect. 2.2.5 (it is not) and that the decay heat (curve) is proportional to the total neutron power at the time the reactor is tripped. Such an assumption does not account for the fact that many of the decay heat precursors take a long tine to build up (or down; to an equilibrium value at any given power. This would wake TAP calculations unduly conservative for highpower transient trips and vice versa for low-power trips.

Sect. 3.1 We belleve that some heat capacity should be included for the high-pressure (HP) and low-pressure (L.P) feed heaters and piping and do not understand why the HP heaters have zero terminal temperature difference (TTD) while the LP heater TTDs are 5 to $10^{\circ} \mathrm{F}$.

The description of the model for the deaerator indicates that the outlet (water) temperature is (Instantaneously) equal to the saturated steam temperature. We belleve that the lag due to the large water inventory would be considerable and should be included.

Sect. 3.2 It may be noted that in several cases where the ORNL steam generator code BLAST has been compared with the TAP model, the results were in good agreement. This is comforting in that the two codes use many different modeling schemes and solution techniques.

Equations 3-32 and 3-33 of the TAP report define a measured or lagged temperature $T_{L}$ by

$$
T_{L}=L P+\frac{T_{A}-T_{L P}}{C},
$$


where

$$
\begin{aligned}
T_{L P} & =\text { value of } T_{L} \text { from previous time step, } \\
T_{A} & =\text { actual temperature. }
\end{aligned}
$$

While the report defines $C$ as a "time constant of the respective lag, (sec)." It should be defined as a factor related to the time constant $\tau$ and the time step interval $\Delta \theta$ by

$$
c=1 /\left(1-e^{-\Delta \theta / \tau}\right)
$$

The TAP code calculation $r$ s is correct.

The report states that for both the helium and the secondary fluid, the nodal average temperatures are taken as the arithmetic mean of the boundary temperatures and the exit boundary temperature for one node is the inlet for the next. For the case of the gas,

$$
\Delta T_{\left.g o\right|_{\text {initial }}}=\frac{1-n / 2}{1+n / 2} \Delta T_{g 1} \text {, }
$$

where $\Delta T_{g o}$ and $\Delta T_{g 1}$ are the initial changes in gas outlet and inlet temperatures, and

$$
\mathbf{n}=\mathbf{h A} / W C_{p}
$$

The value of $n$ grows both with increasing node length ( $\alpha A$ ) and decreasing mass flow rate $w$, since $h / w \propto w^{-0.2}$, at least in the turbulent range. It can be seen from the equation for Intelal changes in gas outlet cemperature that values of $n>2.0$ cause "wrong-way response" of the outlet temperature. Hence, depending on the node lengths and flow ranges encountered, this model may yield nonphysical results. Furthermore, in the case of liquid (with $M C_{P} \gg 0$ ), the initial "wrong-way response" problem would be more pronisunced, since $T_{0}=2 \bar{T}_{1}-T_{1}$, and $\bar{T}$ would not change instantaneously. 
Sect. 6 Hoping that its importance is not underestimated, we would like to add our encouragement to GA's TAP model verification progran. The use of FSV dynanics data to verify TAP will be a difficult task, but could be of long- and wide-range benefit in the designing of models for the gas-cooled fast-breeder reactor (GCFR) and the very-high-temperature gas-cooled reactor (VHTR), as well as for the HTGR. Because of this, we would recomend that more data be acquired $o$. stean generator dynamics (from the FSV specially instrumented module) cian is presently implied from the report.

\section{A.2 REVIEW OF RECA3 REPORT LTR-22}

The following coments supplement the points made in Sect. 3.2 and are Identifled by RECA3 report section number.

Sect. 1. The Introduction gives a good summary of the code capabilities and history of the code development. We belleve, however, that it should note RECA3's dependence on the TAP code for FSV analyses.

Sect. 2.2 It is stated in this section that in accidents analyzed using RECA the reactor is "Imediately tripped." This would imply that a large and significant class of excursions that eventually result in the use of emergency cooling is not covered by RECA. Why not?

Sect. 3. Acknowledging the fact that the ultimate heat sink portion of the CACS is normally designed by an architect-engineer, we think that inclusion of the dynamic behavior of a typical cooling tower in RECA would be desirable to investigate effects of possible cacs startup problems such as icing, etc. 
Sect. 4.1 The discussion of the calculation of the effective mean fluid node temperature in the core model (with elaborations in Appendix A) notes comparisons between RECA's end-point-weighting (EPW) model and an integrated profile (exponential approach) model, which is taken as a reference. A sensitivity study of a postulated DBDA using the ORECA code was made to note the effect of making the EPW assumption. (ORECA normally uses the exponential approach model.) We found, as did GA, that the differences were not signif icant.

The afparent problem with the afterheat decay equation (Eq. 4-8) is discussed in Sect. 3.2 of this report. It should also be noted that if large computation time steps are used, the average, or integrated, value of heat generation over the interval should be used instead of the instantaneous value of the function at the end of the time step.

A term for the coolant r.hannel diameter was apparently omitted from the denominator of the expression for friction loss in Eq. 4-16. It is stated that the coolant outlet temperatures are assumed to be "well mixed" in the plenum. It should be noted that special studies involving potential damage to overheated Iners assume some stratification effects.

Sect. D. In the sensitivity studies showing the effects of varying certain parameters on peak temperatures, the base temperature should be identified in the ratio; that is, is it ${ }^{\circ} \mathrm{F} /{ }^{\circ} \mathrm{F},{ }^{\circ} \mathrm{R} /{ }^{\circ} \mathrm{R}$, or ${ }^{\circ} \Delta \mathrm{T} /{ }^{\circ} \Delta \mathrm{T}$ ?

General. It would have been useful to include a sample RECA3 transient, both to give the reader a clearer 1dea of the response characteristics of a shutdown HTGR and to assure the skeptic that RECA3 is operational. 
REFERENCES

1. A. Bardia and R. C. Potter, TAP: A Progran for Analysis of HTGR Nuclear Steam Supply System Performance Transients, GA-A13248 (GA-LTR21), Jan. 30,1976 .

2. H. W. Chi and G. J. Malek, Description of the Reactor Emergency Cooling Analysts Code, RECA, GA-10273, Aug. 19, 1970.

3. J. F. Peterson, IECA3: A Computer Code for Thermal Analysis of HTGR Emergency Cooling Transients, GA-A14520 (GA-LTR-22), August 1977.

4. J. C. Cleveland et al., ORTAP: A Nuclear Steam Supply System Simulation for the Dynamic Analysis of High-Temperature Gas-Cooled Reactor Transients, ORRL/NUREG/TM-78, September 1977.

5. J. C. Cleveland et al., "ORTAP: A Simulator of High Temperature GasCooled Reactor Nuclear Steam Supply System Dynamics," pp. $359-69$ in Proceedings, 1977 Summer Computer Simulation Conference, July 19-20, 1977, Chicago, I11., CONF-770728.

6. J. C. Cleveland, CORTAP: A Coupled Neutron Kineticg-Heat Transfe: Digital Computer Program for the Dynamic imulation of the HighTemperature Gas-Cooled Reactor Core, ORNL/NUREG/TM-39, January 1977.

7. R. A. Hedrick and J. C. Cleveland, BLAST: A Digital Computer Program for the Dynamic Simulation of the High-Temperature Gas-Cooled Reactor Reheater-Steam Generator Module, ORNL/NUREG/TM-33, August 1976.

8. J. P. Sanders, High-Temperature Gas-Cooled Reactor Safety Studies for the Division of Reactor Safety Research, Quarterly Progress Report, Apr. 1, 1976-June 30, 1976, ORNL/NUREG/TM-43. 
9. J. C. Cleveland et al., "Simulation of the Response of the Fort St. Vrain High-Temperature Gas-Cooled Reactor System to a Postulated Rod Withdrawal Accident," (to be published in Proceedings of the Als Thermai Reactor Safety Heeting, July 31-Aug. 4, 1977, Sun Valley, Idaho).

10. S. J. Ball et al., High-Temperature Gas-Cooled Reactor Safety Studies for the Division of Reactor Safety Research, Quarterly Progress Report, Apr. 1-June 30, 1977, ORNL/NUREG/TM-138.

11. J. R. Brown and R. J. Nirsch1, Fort St. Vrain HTGR Maximum Rod Worth and Rod Withdrawal Accident Calculations for Reactor Thermal Powers from $2 z$ to $100 z$, Gulf-GA-B 10872, July 1972.

12. M. B. Peroomian, A. W. Barse 11, and J. C. Saeger, oxidE-3: A Computer Code for Analysis of HTGR Steam or Air Ingress Accidents, General Atomic Report GA-A12493 (GA-LTR-7), Jan. 15, 1974.

13. R. K. Deremer and T. Shih, RATSAY: A Computer Code to Ana lyze the Transient Behavior of the HTGR Primary Coolant System During Accidents, General Atomic Report GA-A13705, May 1977.

14. S. J. Ball, ORECA-I: A Digital Computer Code for Simulating the Dynamics of HTGR Cores for Emergency Cooling Analyses, ORNL/TM-5159, Apri1 1976.

15. J. F. Petersen et a1., RECA3 Computer Code User's Manual, General Atomic Report GA-A14521 (to be published).

16. J. P. Sanders, Quarterly Progress Report on Reactor Safety Programs Sponsored by the NRC Division of Reactor Safety Research for January March 1975, ORNL/TM-4914, Vol. IV.

17. D. R. Lewis, J. D. Gask1, and R. H, Ross, Chrysler Improved Numerical Differencing Analyses for 3rd Generation Computers, Chrysler Corporation Space Division Report TN-AP-67-287, Oct. 20, 1967. 
18. D. D. Paul, Depressurizat ion Accident Analyes for the Fort St. Vrain Reactor, ORN/NUREG/nt-58, Decewber 1976.

19. R. Brogli and R. Froehlich, "Space and Spectrun Effects for Rod

Renoval Transients in an HTGR," Trans. Amer. Nucl. Soc. 13(1), 282 (June-July 1970). 